\title{
Empirical Research on Growth Factors of County and Township E-commerce
}

\author{
Xiaheng Zhang \\ Business School, Northwest University of Political Science and Law. \\ zhangxiaheng@163.com
}

\begin{abstract}
The counties and townships, with many similarities, can be included into an integral group for research, namely the county and township e-commerce. Through literature review, the paper has proposed the direct and indirect growth factors of the county and township e-commerce, as well as the research hypotheses and the theoretical model of growth level, in combination with the current development situations of the county and township e-commerce. Data was collected by means of questionnaire inquiry and analyzed by use of SPSS21.0 and AMOS21.0 software, verifying the effectiveness of validity and reliability of the measuring tools and the fit between the model and the data. Finally, the research hypotheses were verified, then the factors that may cause greater influence on the growth level of the county and township e-commerce were pointed out.
\end{abstract}

Keywords: county and township e-commerce; growth level; structural equation

\section{Introduction}

In China, the central government's No.1 document is put much attention every year, and it is also the wind vane of the national policy. From 2014 to 2016, the No.1 document is focus on the issue of agriculture and rural areas. It give a greater expression of the county and township e-commerce in the No.1 document in 2016. With the spread of ecommerce across the counties, towns and rural areas (hereinafter referred to as the counties and townships), in particular, the mobile networks and mobile smart phone are popular generally, the shop online has become one of emerge in county and township area, online shopping consumption is a daily consumption behavior of the county and township residents. The county and township e-commerce has become a new blue ocean of ecommerce. The county and township e-commerce plays a great value grow with each passing day in the parts of promoting economic development, meeting the daily consumption of residents, stimulating the county and township comprehensive development, broaden the sales channels of agricultural products. Due to obvious similarities, the counties and townships can be regarded as an integral whole to combine agriculture-related e-commerce and county e-commerce, thus, the county and township ecommerce is proposed. The county and township e-commerce refers in particular to realizing the transportation and distribution of commodities and various related commercial activities, financial activities, etc., by means of offline logistics with the ecommerce platform as a medium of exchange when both sides or either side are located in counties or townships [1]. Counties and townships, with great significance to China, have many similarities and are remarkably different from the urban areas. Researching the county and township e-commerce is of both theoretical and practical significance.

\section{Literature Review}

According to the research results of county and township e-commerce and its relative content, the existing results mainly can be divided into several categories, including the ecommerce of agricultural products, the rural e-commerce, the county e-commerce and the county and township e-commerce, as proposed by some. 
In terms of the e-commerce of agricultural products, Ruiz-Garcia has researched the inquiry and tracking of data of the agricultural product supply chain and put forward the Internet-based management information system [2]; Zhao Ping, et. al.,. have researched China's various strategies to develop the e-commerce of agricultural products, taking " Caiguanjia " and "Freshdirect" as examples [3]; Wen has put forward the intelligent electronic system of agricultural products trade, and innovated the model of agricultural products e-commerce [4]; Luo Yi has found the measures to promote the development of agricultural products e-commerce from the perspective of government [5]; Ge Jun, et. al.,. have analyzed the United States, Japan, the United Kingdom's advanced experience, and found the suggestions for the development of China's agricultural products e-commerce [6]; Li Yanju has put forward the " company + farmer " mode of agricultural products ecommerce development strategy by learning the foreign experience [7]; Zhao Zhitian, et. $a l .$, have researched the logistics of agricultural products e-commerce, and found the logistics information technology is the key to the logistics of agricultural products ecommerce [8].

Regarding the rural e-commerce, Li Lingfang, et. al.,. hold that it is necessary to start with the construction of the rural Internet sales market and the rural e-commerce sales market [9]; Li Chenggang has raised four key elements of the rural e-commerce, namely the peasant, the e-commerce service platform, the market and the Internet [10]; Liu Ke has thought that the rural e-commerce is the basic way of the international and domestic trade of agricultural products, and put forward the basic work of the development of the rural ecommerce in six aspects [11]; Wang Cong has put forward the e-commerce platform model based on the rural cooperative organization [12]; Cheng Xuanmei, et. al., hold that the rural e-commerce can improve the entrepreneurial motivation, reduce the threshold of entrepreneurship, improve the efficiency of entrepreneurship [13]; Guo Chenglong has put forward the symbiotic structure of rural e-commerce with the symbiotic concept [14].

With regard to the county e-commerce, Liu Xueqin, et. al., put forward that the county e-commerce which is combined with the physical retailing can promote the development of the rural e-commerce to the most extent [15]; Xu Chan, et. al., have proposed three modes of the county e-commerce, including the " going to market ", "Land-aggregation mode" and "Shaji mode" [16]. As to the county and township e-commerce, Zhang Xiaheng, et. al.,. have come up with that solving the problem of logistics collaboration can promote the development of the county and township e-commerce; [1] with the collaboration theory as an angle of view, Zhang Xiaheng has brought forward a series of specific strategies for the logistics network of the county and township e-commerce [17]. Ali Research boosts considerable research results, mainly including Rural Online Consumption Research Report (2015), Mini-report of Development of the County Ecommerce, Research Report on Taobao Villages, White Paper on the Ali E-commerce of Agricultural Products, Report on the County E-commerce Development Index in China, Suichang Model Research Report, Research Report on Shaji Collection Model, White Paper on Agricultural Products E-commerce, Yiwu County: from the Emergence of a Market Transition to E-commerce in the County Economy, Report on E-commerce Development of Counties in China, etc.,

With high reference value, the existing researches are discussed from several aspects, and they also have disadvantages as follows: (1) the existing researches are developed from multiple individual levels, regarding the rural, agricultural product, county and other aspects, so the counties and townships fail to be regarded as an integral whole, resulting in separation of the integrity; (2) individual results are developed from the integral angle of view, but the focus is on county and township e-commerce and logistics collaboration; (3) the existing researches lack empirical research and quantitative analysis, which is lack of integrity to study the county and township e-commerce, and also lack of quantitative and empirical research reference. Starting with researching the influential factors of the county and township e-commerce, the data is collected by means of survey questionnaire and analyzed quantitatively by use of SPSS21.0 and AMOS21.0 software and the structural 
equation modeling, so as to reveal and research the influence on and importance of the factors to the county and township e-commerce.

\section{Theoretical Model and Research Hypothesis}

\subsection{Theoretical Model}

The county and township e-commerce is the commodity circulation channel, and it is a goods supply chain from supplier to the consumer. The county and township e-commerce involves many aspects. The ecosystem of the county and township e-commerce is comprised of such links as supplier, consumer, network platform, payment and logistics. The theoretical model is proposed based on the supply chain theory and the ecosystem theory, as shown in figure 1. The growth level of the county and township e-commerce is possibly influenced by many factors, especially the supply chain and the business ecosystem of commodities. The direct factors affecting the growth of county and township e-commerce includes the network platform, payment level, logistics level, supply and consumption level. The infrastructure, concept, product attributes produce deep influence the above direct factors, and they indirectly affect the growth of county and township ecommerce.

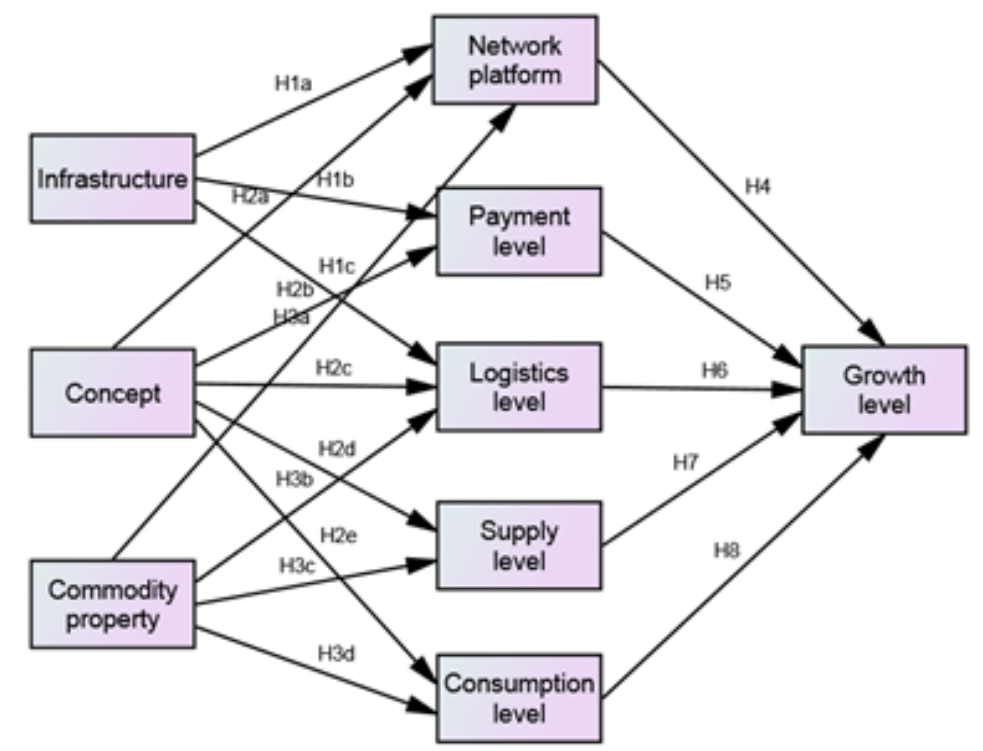

\section{Figure 1. Theoretical Model of Growth Level of the County and Township E-Commerce}

\subsection{Indirect Influential Factors}

Some factors affect the supply chain and the business ecosystem, and thus indirectly affect the growth level of county and township e-commerce. These factors are defined as indirect factors, including infrastructure, concept, product attributes, etc., Indirect impact factors also belong to the category of county and township e-commerce, and they also make direct influence on the core links such as network platform, payment and logistics. The local concept in the counties and townships may also impact the residents' choices of the network platform, payment method, logistics mode and consumption demand [1]. The rural foundation development level possibly changes with the level of such infrastructure as transport, information, network and finance, and probably deeply influences the development level of rural e-commerce [18]. The level of rural infrastructure development will be affected by the level of infrastructure such as transportation, information, network, finance, etc.,, and they also have a deeper impact to the development level of the county and township e-commerce [19]. Based on the aforesaid analysis, here are the hypotheses below: 
H1a: the infrastructure development level has a positive influence on the network platform.

H1b: the infrastructure development level has a positive influence on payment.

H1c: the infrastructure development level has a positive influence on logistics.

$\mathrm{H} 2 \mathrm{a}$ : the concept of the residents of the counties and townships has a positive influence on the network platform.

$\mathrm{H} 2 \mathrm{~b}$ : the concept of the residents of the counties and townships has a positive influence on payment.

$\mathrm{H} 2 \mathrm{c}$ : the concept of the residents of the counties and townships has a positive influence on logistics.

H2d: the concept of the residents of the counties and townships has a positive influence on supply.

$\mathrm{H} 2 \mathrm{e}$ : the concept of the residents of the counties and townships has a positive influence on consumption.

H3a: the commodity property has a positive influence on the network platform.

$\mathrm{H} 3 \mathrm{~b}$ : the commodity property has a positive influence on logistics.

$\mathrm{H} 3 \mathrm{c}$ : the commodity property has a positive influence on supply.

H3d: the commodity property has a positive influence on consumption.

\subsection{Direct Influential Factors}

According to the theory of supply chain, it is a goods supply chain from the supplier, distribution to the consumer. So that, supplier, consumer, distribution channels have become the three key nodes. The network platform acts as a circulation channel, and together with supply and consumption, constitutes the direct influential factors of the development level of the county and township e-commerce. The growth indexes include the e-commerce application, peasant online store, rural online shopping platform construction, etc., Among them, the villagers' e-commerce application is reflected by their online shopping, online payment, online banking and other aspects all of which become the main basis to judge the growth of the rural e-commerce [19]. The rural e-commerce contains four core elements, namely the peasant, the e-commerce service platform, the market and the Internet. ${ }^{[10]}$ Payment and logistics have become the key factors influencing and restraining the development of the county and township e-commerce [17]. Based on the aforesaid analysis, here are the hypotheses below:

H4: the network platform has a positive influence on the growth level of the county and township e-commerce.

H5: the payment level has a positive influence on the growth level of the county and township e-commerce.

H6: the logistics level has a positive influence on the growth level of the county and township e-commerce.

H7: the supply level has a positive influence on the growth level of the county and township e-commerce.

H8: the consumption level has a positive influence on the growth level of the county and township e-commerce.

\section{Research Thought and Model Building}

\subsection{Research Method}

The survey questionnaire is designed according to the scale in combination with the literature analysis, expert opinions and research hypotheses. The research data is acquired by combined use of the field collection and online collection. First, the small sample testing is conducted with 5-point Likert scale questionnaire, with 32 samples chosen from the colleges and network; second, SPSS21.0 and AMOS21.0 are used to analyze the data, then the reliability test is conducted based on the calculation of Cronbach's $\alpha$ coefficient, KMO test and Bartlett sphericity test, and the validity test is carried out based on the 
calculation of standardized factor loading and extracted amount of average variance (AVE value). The structural equation model of the growth level of the county and township ecommerce is constructed, in combination with the verification results.

\subsection{Model Building}

According to the theoretical model above, revision is made in combination with the small sample test results. Then, the structural equation model of the growth level of the county and township e-commerce is built based on AMOS21.0 software, with the observational variables and the error variables shown in Figure 2.

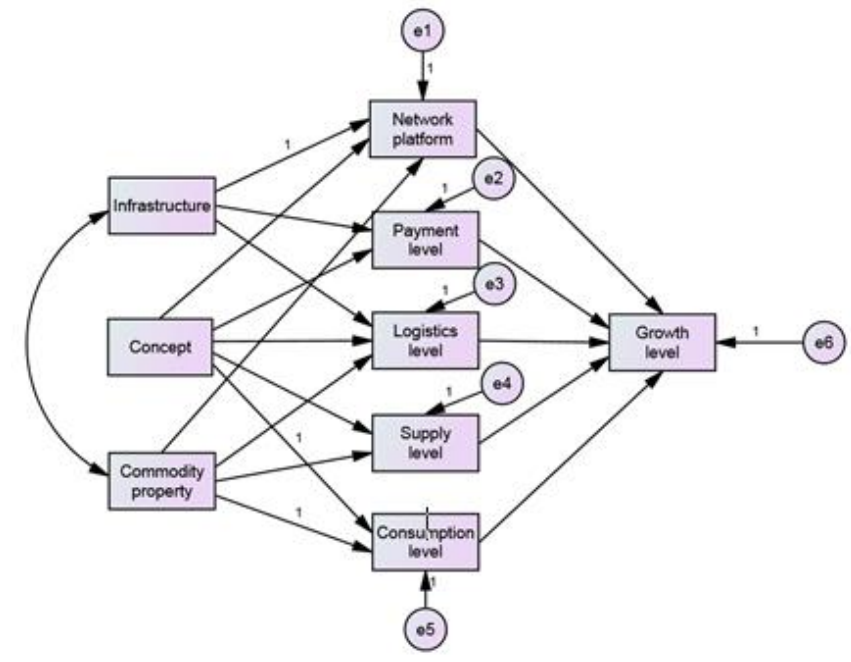

Figure 2. Structural Equation Model of Growth Level of the County and Township E-Commerce

\section{Data Analysis}

\subsection{Data Collection}

By combined use of giving out and retrieving paper questionnaires on site and directionally giving out and retrieving network questionnaires, totally 211 valid samples were obtained mainly from residents of counties and townships, the rural residents and the netizens who bought agricultural products via online shopping. The research subjects are related to the county and township e-commerce [20]. There are more than 200 samples, structural equation model analysis can be used [21-22].

\subsection{Validity and Reliability Test}

SPSS21.0 and AMOS21.0 are used to conduct the validity and reliability test to the collected data. The Cronbach's $\alpha$ coefficient is used for the validity test. As a result, the overall Cronbach's $\alpha$ coefficient is $0.852>0.700$, and the Cronbach's $\alpha$ of all observed variables is more than 0.700 , which indicates that the measuring tool has good validity; the overall KMO is $0.824>0.700$, and KMO of all observed variables is more than 0.700 ; the Sig value of statistics in Bartlett sphericity test is less than 0.01, which indicates significant correlation among the variables and it is appropriate to conduct a factor analysis. The factor is extracted by use of the principal components analysis and selected by means of the maximum variable orthogonal method, the resultant load of observed variables on their attached factors is more than 0.500 , and the composite reliability (CR) of all variables is more than 0.700 and the average variance extraction (AVE) satisfies the minimum requirement of being more than 0.500 , which demonstrates good convergent validity and discriminant validity. Based on the analysis above, the measuring tool designed is considered to have passed the validity and reliability test. 


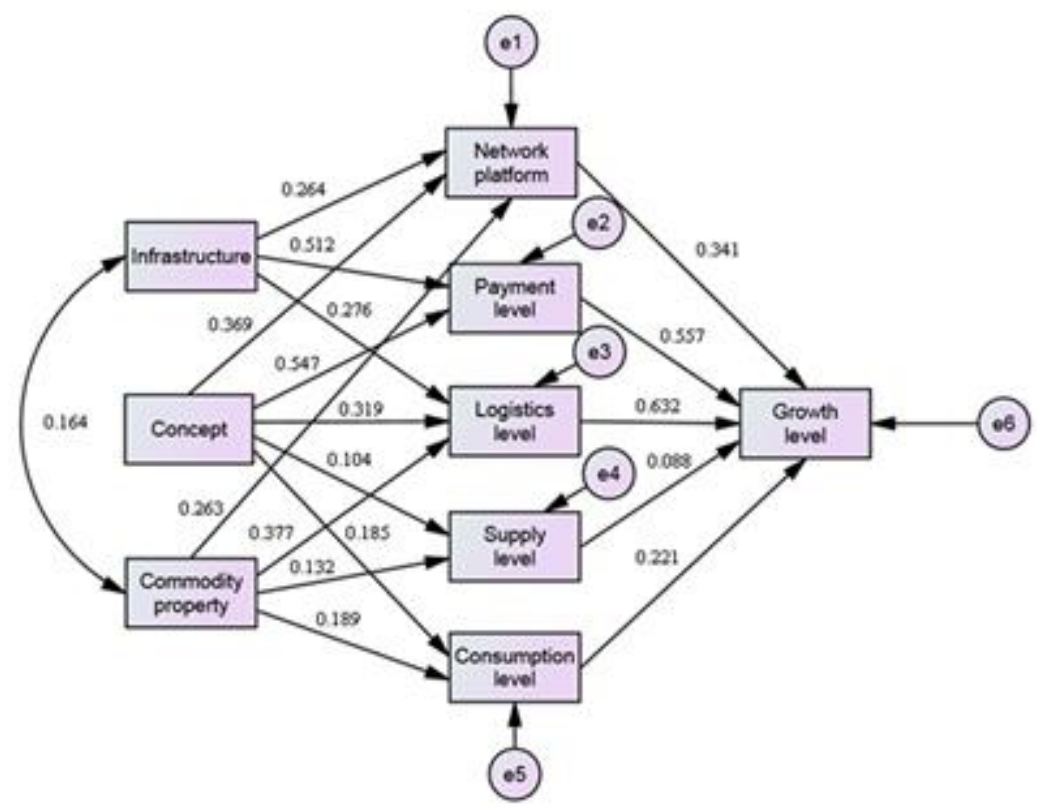

Figure 3. Growth Level Model of the County and Township E-Commerce via the Standardized Estimated Value

\subsection{Good-of-Fit Analysis}

The absolute fit statistics is used to make a fit analysis on the measured data and structural equation model. The statistics mainly includes the chi-square value, GFI, IFI, CFI, RMR and RMSEA. Table 1, shows that the model fits well as a whole, which means that the structural equation model fits the actual research data.

Table 1. Good-of-Fit Test Result

\begin{tabular}{|c|c|c|c|c|c|}
\hline Statistics & $\begin{array}{c}\text { Chi-square } \\
\text { value }\end{array}$ & GFI & IFI & CFI & RMR \\
\hline Index value & $\mathrm{p}=0.463$ & 0.967 & 0.905 & 0.927 & 0.039 \\
\hline Standard & $\mathrm{p}>0.05$ & $>0.90$ & $>0.90$ & $>0.90$ & $<0.05$ \\
\hline $\begin{array}{c}\text { Good-of-fit } \\
\text { analysis }\end{array}$ & Reasonable & Reasonable & Reasonable & Reasonable & Reasonable \\
\hline
\end{tabular}

\subsection{Hypothesis Testing}

The path relationship among all factors is seen in figure 3 . In combination with table 2 , the research hypotheses are verified according to the test standard. The results show that the standardized path coefficient of infrastructure to the network platform is 0.264 , being significant at the level of $\mathrm{p}<0.05$, which indicates that the path is valid, and thus, hypothesisH1a is accepted; the standardized path coefficient of the infrastructure to payment is 0.512 , being significant at the level of $p<0.05$, which indicates that the path is valid, and thus, hypothesisH1b is accepted; the standardized path coefficient of the infrastructure to logistics is 0.276 , being significant at the level of $p<0.05$, which indicates that the path is valid, and thus, hypothesisH1c is accepted; the standardized path coefficient of the concept to the network platform is 0.369 , being significant at the level of $\mathrm{p}<0.05$, which indicates that the path is valid, and thus, hypothesisH2a is accepted; the standardized path coefficient of the concept to payment is 0.547 , being significant at the level of $\mathrm{p}<0.05$, which indicates that the path is valid, and thus, hypothesisH $2 \mathrm{~b}$ is accepted; the standardized path coefficient of the concept to logistics is 0.319 , being significant at the level of $\mathrm{p}<0.05$, which indicates that the path is valid, and thus, hypothesisH $2 \mathrm{c}$ is accepted; the standardized path coefficient of the concept to supply is 0.104 , being 
insignificant at the level of $\mathrm{p}<0.05$, which indicates that the path is invalid, and thus, hypothesisH $2 \mathrm{~d}$ is rejected; the standardized path coefficient of the concept to consumption is 0.185 , being insignificant at the level of $p<0.05$, which indicates that the path is invalid, and thus, hypothesisH2e is rejected; the standardized path coefficient of the commodity property to the network platform is 0.263 , being significant at the level of $p<0.05$, which indicates that the path is valid, and thus, hypothesisH3a is accepted; the standardized path coefficient of the commodity property to logistics is 0.377 , being significant at the level of $\mathrm{p}<0.05$, which indicates that the path is valid, and thus, hypothesisH $3 \mathrm{~b}$ is accepted; the standardized path coefficient of the commodity property to supply is 0.132 , being insignificant at the level of $\mathrm{p}<0.05$, which indicates that the path is invalid, and thus, hypothesisH $3 \mathrm{c}$ is rejected; the standardized path coefficient of the commodity property to consumption is 0.189 , being insignificant at the level of $p<0.05$, which indicates that the path is invalid, and thus, hypothesisH3d is rejected; the standardized path coefficient of the network platform to the growth level is 0.341 , being significant at the level of $p<0.05$, which indicates that the path is valid, and thus, hypothesisH4 is accepted; the standardized path coefficient of payment to the growth level is 0.557 , being significant at the level of $\mathrm{p}<0.05$, which indicates that the path is valid, and thus, hypothesisH5 is accepted; the standardized path coefficient of logistics to the growth level is 0.632 , being significant at the level of $\mathrm{p}<0.05$, which indicates that the path is valid, and thus, hypothesisH6 is accepted; the standardized path coefficient of supply to the growth level is 0.088 , being insignificant at the level of $\mathrm{p}<0.05$, which indicates that the path is invalid, and thus, hypothesisH7 is rejected; the standardized path coefficient of consumption to the growth level is 0.221 , being significant at the level of $\mathrm{p}<0.05$, which indicates that the path is valid, and thus, hypothesisH8 is accepted.

Table 2. Research Hypothesis Testing Result

\begin{tabular}{|c|c|c|c|c|}
\hline Research hypothesis & Estimate & C.R. & $\mathrm{P}$ & Result \\
\hline $\begin{array}{c}\text { H1a: infrastructure } \rightarrow \text { network } \\
\text { platform }\end{array}$ & 0.264 & 2.335 & 0.014 & Accepted \\
\hline H1b: infrastructure $\rightarrow$ payment & 0.512 & 5.028 & $* * *$ & Accepted \\
\hline H1c: infrastructure $\rightarrow$ logistics & 0.276 & 6.332 & $* * *$ & Accepted \\
\hline H2a: concept $\rightarrow$ network platform & 0.369 & 3.847 & 0.007 & Accepted \\
\hline $\mathrm{H} 2 \mathrm{~b}:$ concept $\rightarrow$ payment & 0.547 & 5.552 & $* * *$ & Accepted \\
\hline H2c: concept $\rightarrow$ logistics & 0.319 & 8.365 & $* * *$ & Accepted \\
\hline H2d: concept $\rightarrow$ supply & 0.104 & 1.565 & 0.812 & Rejected \\
\hline H2e: concept $\rightarrow$ consumption & 0.185 & 0.558 & 0.069 & Rejected \\
\hline $\begin{array}{c}\text { H3a: commodity property } \rightarrow \\
\text { network platform }\end{array}$ & 0.263 & 3.337 & 0.002 & Accepted \\
\hline $\begin{array}{c}\text { H3b: commodity property } \rightarrow \\
\text { logistics }\end{array}$ & 0.377 & 2.642 & 0.036 & Accepted \\
\hline $\begin{array}{c}\text { H3c: commodity property } \rightarrow \\
\text { supply }\end{array}$ & 0.132 & 1.312 & 0.154 & Rejected \\
\hline $\begin{array}{c}\text { H3d: commodity property } \rightarrow \\
\text { consumption }\end{array}$ & 0.189 & 1.845 & 0.631 & Rejected \\
\hline $\begin{array}{c}\text { H4: network platform } \rightarrow \text { growth } \\
\text { level }\end{array}$ & 0.341 & 2.417 & 0.006 & Accepted \\
\hline H5: payment $\rightarrow$ growth level & 0.557 & 3.429 & $* * *$ & Accepted \\
\hline H6: logistics $\rightarrow$ growth level & 0.632 & 4.563 & $* * *$ & Accepted \\
\hline H7: supply $\rightarrow$ growth level & 0.088 & 1.824 & 0.095 & Rejected \\
\hline H8: consumption $\rightarrow$ growth level & 0.221 & 2.176 & 0.039 & Accepted \\
\hline
\end{tabular}

Notes: ${ }^{* \star}$ means that $P<0.001$. If $p>0.001$, then the value of $p$ will be shown.

\section{Conclusions and Discussions}


In the growth process, the county and township e-commerce will be affected by many factors. According to the research, the network platform, payment, logistics and consumption are important factors which may influence the growth level of the county and township e-commerce, while supply has less effect on it. During the engagement in the county and township e-commerce, the key points need to be placed in the development, maintenance, promotion and operation of the network shopping platform, and also, the development and satisfaction of the consumer demands and the realization of payment and logistics function require to be emphasized.

The network platform, payment and logistics are influenced by the infrastructure construction and operation level. The infrastructure and equipment are the material basis and also the key elements that influence the network platform, payment and logistics service level, among which payment is under the influence of the infrastructure to the greatest degree. Compared with the urban areas, less banking outlets, lower infrastructure application level and lower popularizing rate of the third-party payment, Internet payment, e-banking payment and other payment methods in counties and townships seriously restrict the development and growth of the county and township e-commerce. The residents in counties and townships keep relatively conservative consumption concept and lifestyle, compared with urban residents, and present remarkable characteristics of "acquaintance society"; what's more, they have low degree of education. Therefore, the residents in counties and townships are apt to the face-to-face payment and payment in cash. As a result, the popularization of the online payment methods is restricted. Commodity attribute has a big impact on logistics, especially some large volume and weight, special commodities cause a great challenge to the application of logistics in county and township areas. Thus, payment and logistics become the most important links which may influence the growth of the county and township e-commerce, and need to be broken through emphatically so as to promote and develop the county and township ecommerce.

The county and township e-commerce is different from the city e-commerce. The Ecommerce was originated in the city. After years of growth, the city e-commerce industry has matured. Under some factors' pushing, liking consumer demand, the state and enterprises' promotion, the lack of urban growth, etc., the e-commerce began to spread from the city to county and township areas. The county and township e-commerce is still in the early stages of development, all aspects are not mature, and they still needs to be further improved. During the development of the county and township e-commerce, all these factors should be focused on and solved by use of resources.

\section{Acknowledgements}

We acknowledge the financial support from the Special research program of Shaanxi Provincial Department of Education of the "Operational Mechanism and Implementation Path of E-commerce in the Precision Poverty Reduction Strategy"

\section{References}

[1] X. H. Zhang and T. S. Ma, "Research on the County and Township E-commerce and the Logistics Development of China with the Synergy View", Contemporary Economy \& Management, vol. 37, no. 7, (2015).

[2] L. Ruiz-Garcia, G. Steinberger and M. Rothmund, "A model and prototype implementation for tracking and tracing agricultural batch products along the food chai", Food Control, vol. 21, no. 2, (2010), pp. 112-121

[3] P. Zhao and Y. Luo, "Case Analysis and Implication of Developing the E-commerce of Agricultural Products - Taking "Caiguanjia" and "Freshdirect" as examples. Journal of Business Economics, vol. 7, (2011).

[4] W. Wen, "A knowledge-based intelligent electronic commerce system for selling agricultural products", Computers and electronics in agriculture, vol. 57, no. 1, (2007), pp. 33-46

[5] Y. Luo, "Study on agricultural e-commerce in China: A research based on cases", China Business and Market, vol. 26, no. 9, (2012). 
[6] J. Ge, F. X. Yan and C. L. Yang, "Study on the development of foreign agricultural electronic commerce modes and lesion to China's electronic commerce development", World Agriculture, vol. 5, (2013).

[7] Y. J. Li, "Analysis of Chinese agricultural product e-commerce model based on international experience", World Agriculture, vol. 7, (2014).

[8] Z. T. Zhao, Y. D. He and J. Z. Yang, "The theory construction and empirical analysis of e-commerce logistics of agricultural products", Journal of Business Economics, vol. 7, (2014), pp. 14-21.

[9] L. F. Li, S.Y. Xu and Z. Q. Hong, "Rural E-commerce: Problems and Solution", Journal of Fujian Provincial Community Party School of CPC, vol. 5, (2013).

[10] Y. L. Zheng and W. J. Pan, "Rural E-commerce Development and Villager Information Consumption Growth Effect", Fujian Tribune • Humanistic and Social Sciences, vol. 11, (2015).

[11] K. Liu, "Research on the development of e-commerce in rural areas", Reform of Economic System, vol. $6,(2008)$.

[12] C. Wang, "Electronic commerce and rural entrepreneurship: Base on the perspective of rural cooperative's electronic commerce platform", Ublic Administration \& Law, vol. 1, (2012).

[13] X. M. Cheng, K. X. Chen and H. C. Lin, "Microscopic mechanism and policy prospects of rural ecommerce to promote inclusive entrepreneurship", Journal of Zhejiang University of Technology(Social Science) vol. 14, no. 1, (2015).

[14] G. Chenglong, "Research on rural e-commerce model based on survey of Taobao village", Reform of the Economic System, vol. 5, (2015).

[15] C. G. Li, "Analysis of Rural E-commerce Mode under "Internet +":, Journal of Commercial Economics, vol. 32, (2015)

[16] X. Q. Liu, H. X. Wu and C. L. Zhang, "Research on County E-commerce Development for Rural Consumer Goods Combined with the Entity", Prices Monthly, vol. 10, (2013).

[17] X. Chan, L. Bin and T. Z. Wen, "Research on the County Local Urbanization and New Rural Development Mode Based on E-commerce", Urban Planning International, vol. 1, (2015).

[18] X. H. Zhang, "Logistics Network Collaboration Strategy for the County and Township E-commerce of China", Techno economics \& Management Research, vol. 8, (2015).

[19] Z. Yaqin, "Principal Component Cluster Analysis on the Infrastructure Development Level of the Rural E-commerce Areas of China", Forum on Science and Technology in China, vol. 1, (2007).

[20] H. S. Pang, "Research on Optimization of B2C E-commerce Service Quality Oriented by Customer Demand", Revista de la Facultad de Ingeniería, vol. 31, no. 6, (2016), pp. 103-113

[21] J. Loehlin, "Latent variable models: An introduction to factor, path, and structural equation analysis", Psychology Press, (2004).

[22] R. O. Mueller, "Structural equation modeling: Back to basics", Structural Equation Modeling: A Multidisciplinary Journal, vol. 4, no. 4, (1997), pp. 353-369.

\section{Authors}

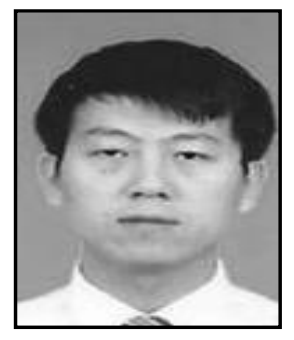

Xiaheng Zhang, Dr. Zhang is working in Business School, Northwest University of Political Science and Law as a lecturer, whose research field is e-commerce. 